\title{
FACTORS EFFECTING EMPLOYEE TURNOVER: A STUDY TO UNDERSTAND ORGANIZATIONAL RETENTION STRATEGIES
}

\author{
Muhammad Khaliq Azam ${ }^{1}$ and Usman Ali Waraich ${ }^{2}$
}

\begin{abstract}
The resignation or leaving of employees, whether better or low performing, created gaps causing understaffing, deterioration of service quality and further overburdening of remaining employees. This research basically aims at exploring and investigating the impact of factors including career growth opportunities, workplace environment, managerial support, rewards \& recognition system, and work-life balance on 'turnover intention' specifically, it will deal with job satisfaction factors such as general working conditions, general working conditions, pay and promotion, work relationships, use of skills and abilities and work activities in relation to job satisfaction and employee turnover. To achieve the research objective, this study utilized the descriptive research design that employed mainly the survey questionnaires to gather information. Key findings revealed that positive significant correlation on the following factors on job satisfaction: pay and promotion, work relationships and the use of skills and abilities positively correlated to employee job satisfaction.
\end{abstract}

Keywords: Employee Turnover, Turnover Intention, Job Satisfaction, Organizational Performance.

\section{INTRODUCTION}

\section{Background of the study}

Almost all leading organizations, irrespective of their size or the nature of business, try to maintain appropriate level of cohesiveness with employees by developing and motivating them. It is a universally recognized fact that long term retention of loyal and committed

${ }^{1 \& 2}$ Institute of Business Management 
employees is the prime consideration of all employers who believe in maintaining a competitive edge through human resource (Firth et al., 2004). Excessive attrition and high turnover intention is neither in the interest of employer nor it is good for career progression of an employee. (Qadir \& Khan, 2016). Employees who leave on the organization's request as well as those who leave on their own initiative can cause disruptions in operations, work team dynamics and unit performance (Ongori, 2007; Samuel, \& Chipunza, 2009). Both types of the turnover create costs for the organization. If an organization has made significant investment in training and developing its employees, that investment is lost when employee leaves. (Iqbal, 2010). In addition to excessive employee turnover can hurt the overall productivity of a firm and is often a symptom of other difficulties. Every organization strives to have high productivity, lesser turnovers and maximum profitability. Managing turnover successfully is a must to achieve the above goals. Abbas and Hollman (2000) stressed that the managers must recognize that employees as major contributor to the efficient achievement of the organization's success. Furthermore, highly motivated and performing individuals are the crucial factors of the organizational productivity. Therefore, there is need to develop a thorough understanding of the employee turnover from the perspective of causes, effect and strategies to minimize turnover. The next section discusses some of the definitions of employee turnover.

\section{Statement of Problem}

The resignation or leaving of employees, whether better or low performing, created gaps causing understaffing, deterioration of service quality and further overburdening of remaining employees. Employee turnover creates a downbeat syndrome for remaining staffs, thereby increasing stress among managers resulting to failure in providing clear guidelines to cope with for the stressed workforce (Nzimande, 2011). 


\section{Research Questions}

- Does your managers or senior management support in your job role?

- Are your rewarded for your success or recognized for your achievement?

- Do you think that extra hard work or task assigned to you and you achieve them, will they help for your career growth?

- Does your organization promote the potential employees?

- Do you think that your organization provide ample of time to complete the objective?

- Does your management provide you limited time to complete multiple tasks either from home or office or beyond work office time?

\section{Objective of Study}

The purpose of this research is to understand the circumstances of employee turnover and the factors which encourage or let the employees to quit the job or leave the current organization from their designation. Certain reason which make the employee to work under the pressure and looking for another opportunity considering the best in comparison of their existing job.

\section{Justification/ Significance of Study}

This research on employee turnover is intended to find out whether employee job satisfaction at the company has an effect on the turnover intentions of employees working across different departments at their current organization. Moreover, the research will assist in determining the reasons behind high rate of employee turnover at their existing organization and provide recommendations to solve the issue. Examining the factors and conditions in relation to employee turnover is an area an aspect that is considered highly crucial for the continued success in terms of organizational performance. The findings will make it clear once and for all whether it is possible for turnover within modern day business organizations to be primarily caused on part of the low level of satisfaction on part of the staff and workers. So, the 
organizational management followed by the HR practitioners will be able to use the findings of the results to formulate effective strategies to first curve job satisfaction in the case that a positive relationship is set in between the variables. This research and its findings on job satisfaction and employee turnover will therefore make a note of the organizational relationships and factors to become much clearer and more evident (Jalagat, Bashayre, Dalluay, \& Pineda, 2017).

\section{Limitation of Study}

It may be the case that the results from the current study have broad or narrow generalizability.

- Therefore, the methodology and procedures from this study should be replicated in other contexts to determine the extent to which the results are specific to the manufacturing facility that was the target of this study or, conversely, are generalizable outside this facility.

\section{LITERATURE REVIEW}

It is necessary to keep track of people that help in building and maintaining a strong organization. The role, position and also the prominence that is given to human resources within any organization

is considered to be a reflection of its overall approach and understanding of how human resources drive organizational processes. In most cases, organizations do understand the value and significance that is usually attached with the human resources that they possess. Although in many cases the organization will succeed to get the human resources who are efficient and effective in the tasks and duties that they are doing within the organizational unit but the key point of challenge comes up when organizations try to make sure that the employees who are good in their jobs and duties will be retained within the company itself. This is where the concept of employee turnover is coming into the picture because it is a concept that is revolving around how exactly an organization will try to capture and keep its workforce with itself rather 
than letting them leave the organization (Jalagat, Bashayre, Dalluay, \& Pineda, 2017). Hypothesis

Hol: there is no relationship between career growth opportunities and turnover intentions.

Hal: there is a significant inverse relationship between career growth opportunities and turnover intentions.

Ho2: there is no relationship between workplace environment and turnover intention.

Ha2: there is a significant inverse relationship between workplace environment and turnover intention.

Ho3: there is no relationship between rewards \& recognition system and turnover intention.

Ha3: there is a significant inverse relationship between rewards \& recognition system \& turnover intentions.

Ho4: there is no relationship between managerial support and turnover intention.

Ha4: there is a significant inverse relationship between managerial support and turnover intention.

Ho5: there is no relationship between work life balance and turnover intention.

Ha5: there is a significant inverse relationship between work life balance and turnover intention.

\section{RESEARCH METHODOLOGY}

\section{Research Design}

This chapter provides an overview or a description of the research methods, designs and approaches used in conducting the research. Research hypotheses are also presented in this section. Sampling methods and how the research was conducted were also discussed in this chapter. 


\section{Type of Research}

The research, being explanatory in nature, is based on primary quantitative data collected from respondents with the help of a well-structured questionnaire.

\section{Method of Research}

In this study, it primarily utilized the quantitative research design using the descriptive survey questionnaires as its main research instrument. The basis of using the quantitative approach is mainly based on the research objective to assess the relationship between the job satisfaction factors, job satisfaction and employee turnover as hypothesized (Creswell, Klassen, Plano Clark, \& Smith, 2011).

\section{Instrumentation}

\section{Reliability and Validity}

According to Cohen et al. (2013) the complete elimination of threats to reliability and validity is not possible however to this extent important measures can be adopted to reduce these threats. Similarly, the following measures for reliability and validate will be applied to this proposed research.

External Validity: external validity is established in the study by adequately considering the sample size for the study as indicated in the above context, by keeping the margin of error are low, its level of confidence high as well as maintaining a moderate level of response rate which is not overly optimistic, the study attempts to expand the external validity. Content Validity: in order to establish the content validity of the study, achievement tests will be devised and applied in conducting the given proposed research. Reliability: in order to establish the reliability of the results, the researcher has proposed to use the test-retest tool, under which the results of the test will be measured with the final outcome of the questionnaires used for the study (Steele, 2003). Although the techniques available for establishing reliability and validity in the context of qualitative research are known to be less precise in comparison to their 
counterparts, the researcher has chosen to use peer evaluation whereby the inferences drawn would be checked by another researcher.

\section{Ethical Consideration}

Ethical Considerations can be specified as one of the most important parts of the research. Dissertations may even be doomed to failure if this part is missing. According to Bryman and Bell (2007); Bryman et al (2007), following ten points represent the most important principles related to ethical considerations in dissertations:

- Research participants should not be subjected to harm in any ways whatsoever.

- Respect for the dignity of research participants should be prioritized.

- Full consent should be obtained from the participants prior to the study.

- The protection of the privacy of research participants has to be ensured.

- Adequate level of confidentiality of the research data should be ensured.

- Anonymity of individuals and organizations participating in the research has to be ensured.

- Any deception or exaggeration about the aims and objectives of the research must be avoided.

- Affiliations in any forms, sources of funding, as well as any possible conflicts of interests have to be declared.

- Any type of communication in relation to the research should be done with honesty and transparency.

\section{Data Analysis Plan}

In the analysis of the primary and secondary data, it was necessary to use basic research instruments. Statistical frequencies were used in providing an overview of the results while the correlation being used was for the purpose of linking variables with each other. On the other 
hand, non-parametric, bivariate, and alternative analysis tools were used in analyzing gathered data. In this case, there are three levels of variable categories to be included: the five factors of job satisfaction namely: General Working Conditions, Pay and Promotion, Work Relationships, Use of Skills and Abilities and Work Activities, job satisfaction and employee turnover. Statistical Package for Social Sciences is used in data calculation. The software has been used by researchers in making accurate calculations of the data gathered to avoid misinterpretation of data. Pearson correlation is used to test the linear dependence or the impact that a variable can have on another variable. It could yield three results (and they're between): 1 for positive total correlation, 0 for no correlation and -1 for total negative correlation. In the same manner, the sig (2-tailed) also tells there is a significant correlation between the two variables being compared.

\section{RESULTS}

\section{Descriptive Statistics}

Descriptive analyses through mean scores of the items according to the construct understudy were calculated. In general, the values of the mean score designated the agreement in the indicators of the survey. In this case, the higher the level of the mean score, it shows that respondents are agreed with what were asked to them. The survey used a 4-point Likert scale thus the values should be in between 1 (lowest) to 4 (Highest). Hence, 2.5 is the intermediate value in between whether respondent is agreed or disagreed with the items. The value more than 2.5 indicates that respondent is agreeing with the items and the value below 2.5 indicating otherwise. In addition, standard deviation reported also means that whether respondents are agreed with the items that were asked and that shows how far it varies among respondents. Therefore, the descriptive analysis conducted gave clear information of the items. 


\section{Inferential Statistics}

With inferential statistics, you are trying to reach conclusions that extend beyond the immediate data alone. For instance, we use inferential statistics to try to infer from the sample data what the population might think. Or, we use inferential statistics to make judgments of the probability that an observed difference between groups is a dependable one or one that might have happened by chance in this study. Thus, we use inferential statistics to make inferences from our data to more general conditions; we use descriptive statistics simply to describe what's going on in our data.

\section{DISCUSSION CONCLUSION AND RECOMMENDATIONS}

\section{Discussion}

This section presents the results and findings of the data obtained from respondents. This section is divided into six sections: General Working Conditions, Pay and Promotion, Work Relationships, Use of Skills and Abilities, and Work Activities. Using SPSS software, data were rendered and calculated to provide a clear understanding of the responses in a way understandable.

\section{Conclusion \& Recommendations}

This study mainly investigates the effects of job satisfaction on employee turnover as applied to the chosen organization, the Oman Air. Main findings revealed that among the main factors namely the general working conditions, pay and promotion, work relationships, use of skills and attitudes, and work relations both positive and negative correlations were derived when analyzed in details the specific variables under these main variables. Generally, factors such as positive significant correlation on the following factors on job satisfaction: pay and promotion, work relationships and the use of skills and abilities positively correlated to employee job satisfaction. 


\section{REFERENCES}

Abbasi, S. M., \& Hollman, K. W. (2000). Turnover: The real bottom line. Public personnel management, 29(3), 333-342.

Bell, E., \& Bryman, A. (2007). The ethics of management research: an exploratory content analysis. British journal of management, 18(1), 63-77.

Bryman, A., Bell, E., Mills, A. J., \& Yue, A. R. (2007). Business research strategies. Business research methods, 226-238.

Cohen, J., Cohen, P., West, S. G., \& Aiken, L. S. (2013). Applied multiple regression/correlation analysis for the behavioral sciences. Routledge.

Creswell, J. W., Klassen, A. C., Plano Clark, V. L., \& Smith, K. C. (2011). Best practices for mixed methods research in the health sciences. Bethesda (Maryland): National Institutes of Health, 2013, 541-545.

Firth, L., Mellor, D. J., Moore, K. A., \& Loquet, C. (2004). How can managers reduce employee intention to quit?. Journal of managerial psychology.

Iqbal, A. (2010). Employee turnover: Causes, consequences and retention strategies in the Saudi organizations. The Business Review, Cambridge, 16(2), 275-281.

Jalagat, R., Bashayre, A., Dalluay, V., \& Pineda, A. P. (2017). Correlates the relationship of service quality, customer satisfaction and customer retention on selected restaurants in Muscat, Sultanate of Oman. The International Journal of Business and Management, 5(9), 97-110.

Nzimande, N. B. (2012). High staff turnover: A study for the Gauteng Department of Finance. Unpublished master's dissertation, University of South Africa, Pretoria, South Africa. 
Ongori, H. (2007). A review of the literature on employee turnover.

Qadir, A., \& Khan, M. M. (2016). Linking personality and emotional labor: The mediating role of relationship conflict and conflict management styles. Pakistan Journal of Commerce and Social Sciences (PJCSS), 10(2), 212-238.

Samuel, M. O., \& Chipunza, C. (2009). Employee retention and turnover: Using motivational variables as a panacea. African journal of business management, 3(9), 410-415.

Steele, M. M., Fisman, S., \& Davidson, B. (2013). Mentoring and role models in recruitment and retention: a study of junior medical faculty perceptions. Medical teacher, 35(5), e1130-e1138. 